\title{
THE APRIL MEETING IN CHICAGO
}

The five hundred ninety-ninth meeting of the American Mathematical Society was held in Chicago, Illinois on April 19 and 20, 1963. All sessions were in Eckhart Hall of the University of Chicago. Meeting headquarters were at the Shoreland Hotel, though Registration was in the Common Room of Eckhart Hall. There were 321 registrants, 282 of whom were members of the Society.

The Committee to Select Hour Speakers for Western Sectional Meetings invited Professor Gerald R. MacLane of Rice University and Professor Walter L. Baily, Jr. of the University of Chicago to address the Society. Professor MacLane spoke at 2:00 P.M. on Friday on Asymptotic values of functions holomorphic in the unit disc with Professor Saunders MacLane presiding. Professor Baily spoke at 2:00 P.M. on Saturday On automorphic functions and the problem of moduli with Professor Alberto P. Calderon presiding.

Sessions for the presentation of contributed papers were held at 3:15 P.M. on Friday and Saturday and 10:00 A.M. on Saturday. Presiding officers were Professors R. H. Bruck, Eldon Dyer, Israel N. Herstein, P. R. Masani, John Roberts, and Herman Rubin.

Members of the Society were guests at a tea held by the Department of Mathematics in the Quadrangle Club on Friday afternoon. 